\title{
Adult learners' intention to adopt mobile learning: A motivational perspective
}

\begin{abstract}
Mobile learning (m-learning) is gaining popularity as the 'anytime, anywhere' online learning channel. Academics and practitioners alike are showing interest in examining its ability to support online learning. However, prior studies have highlighted the challenges in promoting m-learning adoption. The extantm-learning literature has mainly focused on technology related factors to examine m-learning adoption. However few studies have investigated this topic from the users' motivation perspective and even fewer from an adult learner context. Hence this study employsthe Uses and Gratification Theory to provide a betterunderstanding of what motivates m-learning adoptionin adult learners. The research findings suggest that adult learners' intention to use m-learning is influenced by their affective needs and social integrative needs through attitude. This paper concludes by noting the theoretical and practical contributions.
\end{abstract}

Keywords: Mobile learning, Uses and gratification theory, Adult learners and Technology adoption

\section{Introduction}

With today's world that puts so much emphasison efficiency and mobility - people are relying more heavily on the use of mobile technologies (Liu, Li, \& Carlsson, 2009). Mobile technology is acknowledged as the emerging technology stream that plays an increasingly important role in business and society (Chin, 1998; Scornavacca, Barnes, \& Huff, 2006).In recent years, there is emerging interest shown by academic and practitioner communities on the ability of mobile technology to carry out online learning activities (Morris, 2010; Petrova \& Li, 2009). In general, mobile learning (m-learning) is defined as the delivery of learning activities to students anytime and anywhere through the use of mobile devices (Wang, Wu, \& Wang, 2009). M-learning can take place through the use of applications such as mobile phones, personal digital assistants (PDAs), smart phones, tablets and portable multimedia players. According to Park, Nam and Cha (2012), m-learning is a new and independent part of e-learning where the education content are handled solely by mobile technology devices.

Although m-learning is gaining popularity as the next emerging technology to support online learning, a recent study reveals that there are actually challenges. Among them are- promoting the adoption of m-learning (Huang, Lin, \& Chuang, 2007; Liu, Han, \& Li, 2010; Liu, Li, \& Carlsson, 2009); students' readiness to accept the use of m-learning (Corbeil \& Valdes-Corbeil, 2007); and technology restrictions (Siau, Lim, \& Shen, 2001).Out of these challenges, this study is interested in the m-learning adoption issue as previous works are highlighting this issue as an issue that has been largely ignored and promoting m-learning adoption is becoming increasingly a challenge for providers(i.e. academic institution) (Chin, 1998; Liu, 2008; Tenenhaus et al., 2005). Furthermore, previous works are more directed atexamining the adoption issue from e-learning compared to m-learning context (Chin, 1998).

Currently, our observation of the m-learning adoption literature shows that the understanding of what influence students' adoption behaviour is heavily dominated by works that focus on technology related enablers (Chin, 1998; Huang, Lin, \& Chuang, 2007; Liu, Han, \& Li, 2010; Liu, Li, \& Carlsson, 2009). For instance, most of previous works adoptedinformation system (IS) adoption theories to ground their study (e.g., Technology Acceptance Model). Limiting the understanding only to technology related enableris not likely to provide a clear understanding of what influence students'intention to adopt m-learning. This is because today's students are becoming more complex; thus requires the researcher to look beyond technology related enablers (e.g., motivation, social).

Thus, in order to get a clearer understanding of what influence adult learners' decision to adopt m-learning, this study proposed to examine this issue from a motivation perspective. In this study, motivation related enablers are selected because it have been identified as an essential perspective to help understand why users prefer certain learning platforms compared to others (King, 2002). Hopefully by examining this issue based on motivation related enablers, this study can add new insightsto the exisiting body of knowledge. 
Further, this study is also different from others as it focuses on the adoption of m-learning by adult learners. This study defines adult learnersas students who are over the age of traditional students (18 to 21 years old) (Kasworm 1990; Katz, Blustain, Duderstadt, Farrington, Goldstein, Graves, \& Lozier, 1999).One of the reasons why adult learners is selected because they face difficulties with online learning as many institutions tailor their online programs to support the needs of traditional aged students (Morris, 2010). Based on the adult learners literature, this group of students have been identified to have a different set of needs compared to traditional students (Eastmond, 1998). Adult learners are also said to exhibit significant differences in their academic and live involvement compared to traditional students (Song \& Fox, 2005). Thus examining their needs of using m-learning is essential so that it can help institutions in promoting the use of mobile application as one of the medium to support their learning activities. In addition, it can also help institutions from wasting their money developing tool that will received strong rejection from students.

Finally, this study contributes to the m-learning adoption body of knowledge in two ways: 1) this study extends the current understanding of m-learning adoption by examining this issue from a motivational perspective; and 2) to the best of our knowledge, this can be considered as the first approach taken to examine m-learning adoption in theadult learner context. In order to do so, this studyemployedUses andGratification Theory (UGT)as the underlying theory as it has been widely used to examine user motivations to use an IS. This theory has also been used to examine students' motivation to use IS for learning purposes. For instance, UGT wasused to examine internet adoption for distance learning (Stafford, 2005); the use of computer mediated communication media for learning purposes among university students (Guo, Tan, \& Cheung, 2010); and the use of virtual community as students' learning resources (Mondi, Woods, \& Rafi, 2008).

This paper is organized as follow. The first (this) section outlines the research motivations. The second section discusses previous studies related to m-learning adoption. The third section outlineshow UGT dimensions can be used to explain adult learners' motivation to use m-learning. Based on the discussion in previous sections, a research model is then presented. The final section concludes by noting the research theoretical and practical contributions.

\section{Literature Review}

\section{M-Learning Adoption}

According to Park et al. (2012), the rapid advancement of information and communication technologies (ICT) is changing the landscape of how learning is delivered to students. Education providers are using ICT as alternative mediums to conventional face to face interaction between professor and students within a classroom setting. M-learning is said to widen the spectrum of education by offering learning activities beyond the four walls of a classroom. Through m-learning students can participate in learning activities - everywhere, anywhere (Tenenhaus et al., 2005).In recent years, there are growing numbers of studies on m-learning adoption. For instance, Park et al (2012) examined the factors that influence Korean university student intention of using m-learning. Their study revealed that Korean student intention to adopt m-learning is determined by their perceived usefulness, system accessibility, subjective norms and attitude to use m-learning. Ozdogan, Basoglu and Ercetin (2004) identified perceived usefulness as the strongest determinant for students intention to adopt m-learning. Liu et al. (2010), identified that China university students intention to adopt m-learning is influenced by personal innovativeness and long and short-term usefulness of the tool. Lawrence et al. (2002) outlined four factors that is considered important by Australian university students in order to adopt m-learning; technology availability; effort involved when using the tool; technology control and convenience; the input and output mechanism; and privacy and security issues.

Two major observations can be made from the literature: 1) prior research that examine m-learning tended to focus heavily on the use of technology related enablers to explain students' intention to adopt m-learning; and 2) majority of these works surveyed traditional age students, who are doing their first degree program. Hence, this study proposes to extend the existing body of knowledge by examining m-learning adoption from a motivational perspective (using uses and gratification theory) in the context of adult learners.

\section{Adult Learners}

Based on the adult learning literature, adult learners can be characterized as self-directed, highly motivated and know what they want to achieve from their education program(Huang, 2002). These students are usually over the age of 21 and usually working either full time or part-time (Katz et al., 1999). These students are motivated by career development, job security, 
upward mobility, re-careering and other professional and personal reasons(Eastmond, 1998). Adult learners are usually aided by their life experience; and that their reflections and actions are integral components of the adult learning process (Merriam \& Caffarella, 1991).

According to Ruey (2010), for the online learning process to be successful, adult learner should be able to interact with the course materials; discuss and collaborate between instructor and other students; and integrate their past experience with the course content or assignment. Adult learners enjoy having discussions and relating course material to their lives, use their experiences as a learning resource, problem-centered, and prefer "immediacy of application" (Morris, 2010). In other words, to actively engage adult learners in online learning the program should be able to encourage them to discuss, argue, negotiate ideas, and to collaboratively solve problems (Ruey, 2010). This approach is said to be appropriate for adult learners because their learning context usually require them to integrate their rich life and employment experiences in learning. Thus to make adult online course a success, the tools used should be able to support these needs. Tools that offer these needs are said to have better likelihood to be used and adopted by adult learners (Eastmond, 1998; Huang, 2002).

\section{Uses and Gratification Theory (UGT)}

UGT is a popular theory for studying individual motivation and behavior when using media in the communications domain (Lin, 1999; Stafford, Stafford, \& Schkade, 2004). Based on this theoretical lens, students' motivation to use a media can be categorized into three main categories: 1) cognitive need, 2) social need, and 3) affective need. Empirical evidence shows that these attributes can generally be applied to any media usage - including media technologies used in online learning context (Guo, Tan, \& Cheung, 2010; Guo, Zhang, \& Stevens, 2009; Mondi, Woods, \& Rafi, 2008). For instance, to fulfill cognitive needs, the tool (i.e., m-learning) should be able to motivate adult learners to seek information, knowledge that is related to the course. On the other hand, to fulfill social integrative need, the tool should be able to motivate adult learners to interact with other students in order to promote collaborative learning. While to fulfill affective need, the tool should be able to capture the feeling of personal fulfillment using the medium during the learning process. Due to the importance of collaboration among adult learners, sharing their personal fulfillment about how the medium is able to help them construct new knowledge can increase the likelihood of students adopting the medium (i.e. m-learning).

In addition, it is important to acknowledge that this theory (i.e., UGT) is not the only theory that can be adopted to examine adult learner's motivation to use e-learning application. From the literature review, it shows that a number of researchers that focus on this topic used Keller's motivation model (Motiwalla, 2007)as their underlying theory. In general, this theoretical model evaluates user's motivation from instructional and managerial perspectives. A comprehensive evaluation process is conducted based on student's actual experience using the e-learning application. For instance, using this theoretical model a researcher can assess student's major motivation (i.e., attention, relevance, confidence and satisfaction) using the e-learning application. However in the context of this study, the implementation of m-learning application is still at infancy level and most of faculty members used it (i.e., m-learning application) as a supporting teaching tool. Hence, adopting Keller's motivation model might give different interpretation of user's motivation to adopt this application.

\section{Research Model and Hypotheses}

Based on the proposed research model, adult learner's intention to adopt m-learning is influenced positively by their attitude. Attitude on the other hand is influenced positively by cognitive, affective, and social needs.

Students' intention to adopt m-learning is positively influenced by their attitude. This positive relationship has been identified in previous works that examined online learning adoption (Huang, Lin, \& Chuang, 2007; Liu, Han, \& Li, 2010; Liu, Li, \& Carlsson, 2009). In m-learning context, attitude has been identified as an important factor determining students' m-learning adoption intention (Chin, 1998). Hence based on the above discussions the following hypothesis is proposed:

Hypothesis 1: Adult learners' attitude has a positive influence on their intention to adopt m-learning 
Cognitive need refers to students' motivation to use a medium to seek for information in order to be critical and creative thinkers (Mondi, Woods, \& Rafi, 2008). Students are more likely to have positive attitude towards adopting a medium if it (the medium) is able to provide them with a wide range of information and also ensured the quality and accuracy of the information. Hence based on above discussions the following hypothesis is proposed:

Hypothesis 2: Adult learners' cognitive need has a positive influence on attitude to adopt m-learning

Affective need refers to students' personal fulfillment of using the media towards knowledge construction during the learning process(Mondi, Woods, \& Rafi, 2008). Students are more likely to have positive attitude towards adopting a medium if it is able to encourage learners to achieve personal fulfillment and pleasant experience when using the medium during learning activities. Hence based on the above discussions the following hypothesis is proposed

Hypothesis 3: Adult learners' affective need has a positive influence on attitude to adopt m-learning

Social need refers to students' motivation to use a medium that is able to assist them to interact and collaborate with other fellow students during the teaching and learning process. Students are more likely to have positive attitude towards adopting a medium, if it is able to assist them in making a consensual meaning and co-creation knowledge. A medium that is able to support across time and space communication is said to be able to fulfill student social needs (Guo, Tan, \& Cheung, 2010). Hence based on the above discussions the following hypothesis is proposed

Hypothesis 4: Adult learners' social need has a positive influence on attitude to adopt m-learning

\section{Methodology}

Data Collection

The research instrument for this study was adopted from previous works (Mondi, Woods, \& Rafi, 2008). The research instrument consisted of 22 items. This research measurement is adopted because it focused specifically towards understanding user's motivation to adopt e-learning as medium of learning. However, few modifications were made to the original items to ensure it fitted into the context of this study. As a result, twenty minor wording changes are made and no items were removed or added. Furthermore, all items are measured using seven-point Likert scales ranging from "strongly disagree" (1) to "strongly agree" (7).

The content validity of the instrument is established by consulting a group of experts (i.e. 1 IS professors, 2 Senior lecturer) in the field of IS and mobile learning. They were asked to comments on the research instrument. From the discussions, few minor wording changes were made and no items were removed or added. Meanwhile, a pilot survey was conducted to establish the reliability of the research instrument. The pilot survey follows the procedures of the real data collection phase. The pilot survey only involved 25 postgraduate students studying in one of the university in New Zealand. The measurement and structural model were analyzed (using SmartPLS); and from the analysis the research instruments indicated satisfactory reliability and validity of the measures.

This study used web survey as the main method to collect data. The web survey was open to respondents for almost 2 months. Adult students doing both undergraduate and postgraduate degree from a university in the United States were invited to participate in this web survey. In total, 255adult students participated in the web survey. Out of that only 191 responses were completed and can be used for data analysis.

Partial Least Square (PLS) is suitable when the research objectives focused on: i) identifying the best prediction of relationships between variables and; ii) to test/predict the theoretical model that has been suggested based on the literature and not to test which alternate model fits the data better (Sosik, Kahai, \& Piovoso, 2009). Since the main objective of this study is to predict factors influencing adult learners' motivation to adopt m-learning, thus PLS was selected as the analysis technique. This study used Smart PLS 2.0 as the statistical software to analyze the measurement and structural model. This study follows the standard reporting technique as suggested by PLS scholars(Chin, 2010). 


\section{Results}

Demographic Information

As for this study, majority of the respondents were female (65\%). With $39.2 \%$ aged between 25 to 34 years old, $49.2 \%$ aged between 35 to 49 years old and $11.6 \%$ were aged between 50 to 64 years old. Further, $85.9 \%$ were adult postgraduate (PG) students while the remaining were adult undergraduate (UG) students.67.1\% of the respondents were full time workers and $32.9 \%$ were part timers. All respondents have had experience using mobile learning devices for learning purposes.

Based on the demographic analysis, the respondents for this study is over represented by female compared to male. In order to ensure the reliability of this study, an additional analysis (i.e., ANOVA) is conducted to examine the mean differences between male and female in their decision to adopt m-learning. Our analysis shows that there is no significant differences between male and female. This result is not supprising as there are previous studies (Perse \& Courtright, 1993; Tenenhaus et al., 2005)that shows similar results. One of the pausible explanation for this, is because gender will not influence user's decision to adopt an IS when both male and female users are equally motivated to adopt the IS. Perhaps in the context of this study, both male and female students are motivated to use the m-learning applications for learning purposes.

\section{Measurement Model}

The quality of the measurement model was analyzed based on its convergent and discriminant validity. The convergent validity was evaluated based on Fornell and Larcker's (1981) two criteria: (1) all the indicators must be significant (at least at 0.05 value) and their loading should exceed 0.7 and (2) average variance extracted (AVE) by each construct should exceed the variance due to measurement error for that construct (in other words, the AVE should exceed 0.50). Table 2 demonstrates that all item loadings exceed 0.7 on their respective construct and are all significant at the level of $\mathrm{p}<0.001$. Also the AVE values are above 0.50, ranging from 0.7416 to 0.8684 . Hence both criteria for convergent validity are satisfied.

Meanwhile as for discriminant validity, it was evaluated using one of the most commonly used criteria in PLS: the square root value of the AVE for each construct should be greater than the inter correlations between constructs in the model (Chin, 1998). The square root value of AVE for each construct are bolded in Table 3. The analysis shows all AVE square root values are greater than the intercorrelation values between constructs. Hence the criterion for discriminant validity is satisfied.

\section{Structural Model}

Figure 1 shows the results of the structural model. The model explains a significant amount of variance in the dependent variable, intention to adopt m-learning $\left(\mathrm{R}^{2}=0.637\right)$ and attitude $\left(\mathrm{R}^{2}=0.418\right)$. Adult learners' m-learning adoption intention is strongly influenced by their attitude $(\beta=0.798, \mathrm{p}<0.001)$. Meanwhile adult learners' attitude is significantly influenced by social need $(\beta=0.324, p<0.001)$, cognitive need $(\beta=0.306, p<0.001)$ and affective need $(\beta=0.136, p<0.05)$. All the proposed hypotheses received significant statistical support. 
Table 2: Items loading, CR and AVE values

\begin{tabular}{|c|c|c|c|c|c|c|}
\hline Construct & Items & Questions & Loading & T-Statictic & $\mathbf{C R}$ & AVE \\
\hline \multirow[t]{4}{*}{$\begin{array}{l}\text { Cognitive } \\
\text { need }\end{array}$} & CN1 & $\begin{array}{l}\text { I use my mobile device to help me know many } \\
\text { things }\end{array}$ & 0.870 & 31.621 & \multirow[t]{4}{*}{0.9198} & \multirow[t]{4}{*}{0.7416} \\
\hline & $\mathrm{CN} 2$ & $\begin{array}{l}\text { I use internet on my mobile device to search for } \\
\text { new information }\end{array}$ & 0.895 & 29.688 & & \\
\hline & $\mathrm{CN} 3$ & $\begin{array}{l}\text { I carry out internet search through my mobile } \\
\text { device to answer questions coming from class } \\
\text { discussions }\end{array}$ & 0.810 & 22.174 & & \\
\hline & CN4 & $\begin{array}{l}\text { I use internet on my mobile device to explore } \\
\text { topics of interest, beyond my normal school } \\
\text { assignment }\end{array}$ & 0.868 & 36.122 & & \\
\hline \multirow{4}{*}{$\begin{array}{l}\text { Affective } \\
\text { need }\end{array}$} & AN1 & I like to talk to others about mobile technologies & 0.946 & 108.727 & \multirow[t]{4}{*}{0.9564} & \multirow[t]{4}{*}{0.8459} \\
\hline & AN2 & $\begin{array}{l}\text { I like showing my friends how to use mobile } \\
\text { device in different ways }\end{array}$ & 0.955 & 128.636 & & \\
\hline & AN3 & $\begin{array}{l}\text { Mobile based courseware layout, animation and } \\
\text { illustrations are good to look at }\end{array}$ & 0.863 & 29.304 & & \\
\hline & AN4 & I enjoy learning using a mobile device & 0.912 & 50.447 & & \\
\hline \multirow[t]{4}{*}{ Social need } & SIN1 & $\begin{array}{l}\text { Using e-mail on mobile device give me the } \\
\text { feedback I need from others }\end{array}$ & 0.949 & 72.755 & \multirow[t]{4}{*}{0.9643} & \multirow[t]{4}{*}{0.8711} \\
\hline & SIN2 & $\begin{array}{l}\text { I use e-mail on mobile device to interact with my } \\
\text { friends }\end{array}$ & 0.944 & 63.009 & & \\
\hline & SIN3 & $\begin{array}{l}\text { Mobile internet prepares me to join the extended } \\
\text { learning community outside the class }\end{array}$ & 0.923 & 48.318 & & \\
\hline & SIN4 & $\begin{array}{l}\text { Using mobile device improves my ability to } \\
\text { communicate with other people }\end{array}$ & 0.916 & 41.463 & & \\
\hline \multirow{3}{*}{$\begin{array}{l}\text { Attitude to } \\
\text { adopt } \\
\text { m-learning }\end{array}$} & ATT1 & I like the idea of using mobile device for learning & 0.898 & 43.478 & \multirow[t]{3}{*}{0.9519} & \multirow[t]{3}{*}{0.8684} \\
\hline & ATT2 & Using mobile device for learning is a wise idea & 0.897 & 41.586 & & \\
\hline & ATT3 & $\begin{array}{l}\text { Using mobile device give me a pleasant } \\
\text { experience }\end{array}$ & 0.888 & 38.360 & & \\
\hline \multirow{3}{*}{$\begin{array}{l}\text { Intention to } \\
\text { adopt } \\
\text { m-learning }\end{array}$} & INT1 & $\begin{array}{l}\text { I intend to use mobile device for learning in the } \\
\text { future }\end{array}$ & 0.918 & 53.809 & \multirow[t]{3}{*}{0.9519} & \multirow[t]{3}{*}{0.8684} \\
\hline & INT2 & $\begin{array}{l}\text { I will use the mobile device for learning in the } \\
\text { future }\end{array}$ & 0.940 & 70.650 & & \\
\hline & INT3 & $\begin{array}{l}\text { I will regularly use mobile device for learning in } \\
\text { the future. }\end{array}$ & 0.937 & 83.717 & & \\
\hline
\end{tabular}

Table 3: Intercorrelation Matrix and AVE Square Root values

\begin{tabular}{|l|l|l|l|l|l|}
\hline & CN & AN & SN & ATT & INT \\
\hline CN & $\mathbf{0 . 8 6 1 1}$ & & & & \\
\hline AN & 0.5912 & $\mathbf{0 . 9 1 9 7}$ & & & \\
\hline SN & 0.5523 & 0.4663 & $\mathbf{0 . 9 3 3 3}$ & & \\
\hline ATT & 0.5659 & 0.4684 & 0.5568 & $\mathbf{0 . 9 3 1 9}$ & \\
\hline INT & 0.5267 & 0.4963 & 0.5422 & 0.7979 & $\mathbf{0 . 9 3 1 9}$ \\
\hline
\end{tabular}




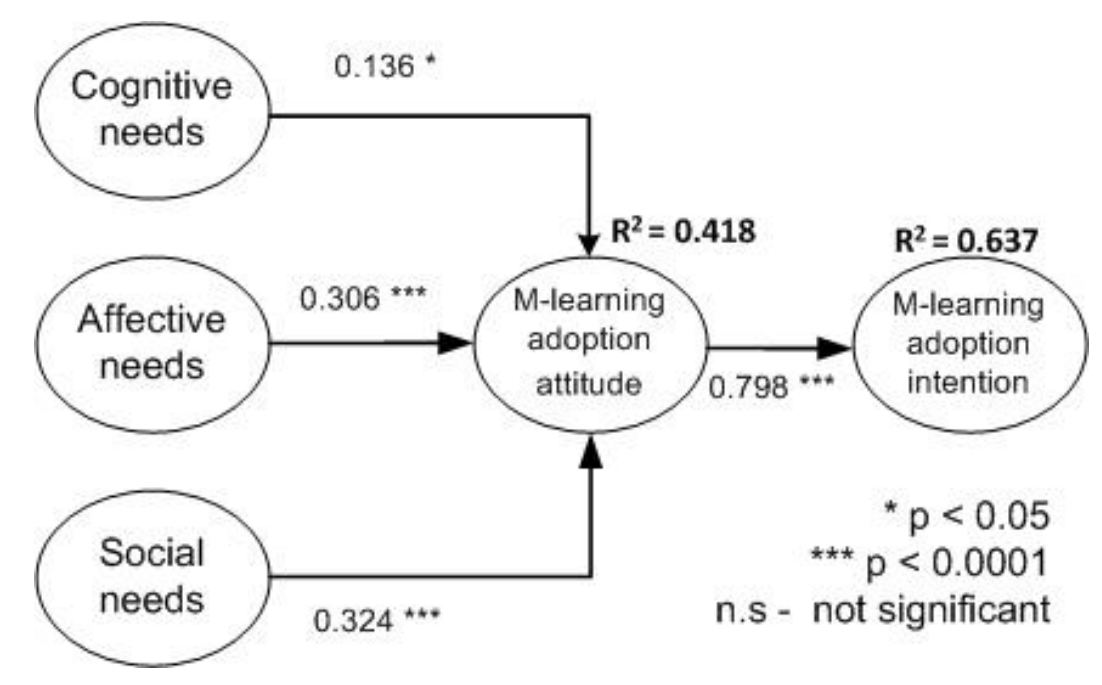

Figure1: Result of Structural Model

\section{Discussions and Conclusions}

This study was conducted to examine the influence of motivational determinants on adult learners' intention to adopt m-learning. Based on the literature review, this study posited that adult learners' intention to adopt m-learning is influenced by cognitive, affective, and social needs through attitude.

Based on the results, this study demonstrated that adult learners have a strong preference to adopt m-learning for learning purposes. The ability of the technology to support adult learners who are always travelling and engaged with work and family contributed to their strong intention to adopt m-learning (Huang, Lin, \& Chuang, 2007). Thus to drive adult learners' motivation to adopt m-learning, attention should be given towards the three instrumental motivation dimensions proposed in UGT namely: social, affective and cognitive needs. From the findings, adult learners are most likely to adopt m-learning if the medium is able to support their interaction needs. Being a student and also working at the same time required them to expand connectivity which allows them to connect and collaborate with other students (Guo, Tan, \& Cheung, 2010). Besides that, adult learner's decision to adopt m-learning is also strongly influenced by the ability of the medium to allow them achieved personal fulfilment and pleasant experience when using the medium. Technology used to support learning should not be too complicated and able to allow them to have positive personal fulfillment towards knowledge construction during the learning process (Mondi, Woods, \& Rafi, 2008). Also, the m-learning medium should be able to provide assistant to adult learners in seeking accurate and quality information. Above all, the results of this study are in line with previous studies (Guo, Tan, \& Cheung, 2010; Huang, Lin, \& Chuang, 2007; Mondi, Woods, \& Rafi, 2008; Stafford, Stafford, \& Schkade, 2004).

Theoretically, the main contribution of this paper is to extend the understanding of what motivate adult learners to adopt m-learning. This is an early attempt at examining adult learners" m-learning adoption intention. Also, the findings of this study are able to provide researchers and practitioners with new insights of what influence adult learners' attitude to adopt m-learning.

In practical terms, this study can help practitioners motivate adult learners to adopt m-learning. From the results, adult learners' attitude to adopt m-learning can be increased by i) integrating the m-learning platform with other means of collaborative applications (i.e., Wiki, Facebook, Twitter) that allow them to work in group. Based on the survey, adult learners are using e-mail as one of the important medium to communicate and work collaboratively; ii) the m-learning platform should allow adult learners to personalize and customize the platform so that it can support different learning styles and preferences; and iii) providing adequate learning resources that is supported by the m-learning platform. This is because the finding suggests that adult learners are using mobile technology to acquire information related to the course.

Finally, the results of this study must be interpreted with some caution. The limitations are: 1) the results are not generalizeable as this study only collected data from one higher education institute; and 2) the students involved in this study 
are from a developed country and as such are more exposed to mobile technology advancements. Perhaps the results might not be the same if this study is replicated other countries (i.e., developing countries). In addition, a comparative analysis should also be conducted to see the differences in motivation between normal cohort students and adult learners. It might be helpful for future research to examine the differences in motivation needs between these two cohorts of student (traditional vs. adult learners). Examining these differences is worthwhile as it can give better understanding on how these two cohorts are different when it comes to m-learning adoption decision.

As a conclusion, m-learning can be seen as among the suitable mediums to widen the spectrum of learning. The need to understand how to promote this technology in order to support adult learning is essential. Perhaps as future research, researchers are encouraged to include social related enablers (inter personal communicative skills, interdependence of task (Ryu \& Parsons, 2009) in their predictive model so that a more holistic understanding of what influence adult learners intention to adopt m-learning can be form.

\section{References}

Bryant, J. (2002). Entertainment as Media Effect. In Media Effects: Advances in theory and Research (pp. 525-544). Hillsdale, NJ: Lawrance Erlbaum.

Chin, W. W. (1998). The partial least squares approach to structural equation modelling. In G. A. Marcoulides (Ed.), Modern Methods for Business Research. Mahwah: Lawrence Erlbaum Associates.

Chin, W. W. (2010). How to write up and report PLS analyses. In V. E. Vinzi, W. W. Chin, J. Henseler, \& H. Wang (Eds.), Handbook of Partial Least Squares (pp. 655-690). New York Springer

Corbeil, J. R., \& Valdes-Corbeil, M. E. (2007). Are you ready for mobile learning? Educause Quarterly, 30(2), 51-58.

Eastmond, D. V. (1998). Adults learners and internet-based distance education. New Direction for Adult and Continuing Education, 78, 33-41.

Fornell, C., \& Larcker, D. F. (1981). Evaluating structural equation models with unobservable and measuremenr error Journal of Marketing Research, 34(2), 161-188.

Guo, Z., Tan, F. B., \& Cheung, K. (2010). Student's uses and gratifications for using computer mediated communication media in learning contexts. Communications of Association for Information Systems, 27(1), 339-378.

Guo, Z., Zhang, Y., \& Stevens, K. J. (2009). A 'uses and gratifications' approach to understanding the role of wiki technology in enhancing teaching and learning outcomes Symposium conducted at the meeting of the ECIS 2009 Retrieved from http://aisel.aisnet.org/ecis2009/77

Huang, H.-M. (2002). Towards constructivism for adult learners in online learning environments. British Journal of Educational Technology, 33(1), $27-37$.

Huang, J.-H., Lin, Y.-R., \& Chuang, S.-T. (2007). Eluciding user behavior of mobile learning: A perspective of the extended technology acceptance model. User Behavior of Mobile Learning, 25(5), 585-598.

Katz, R., Blustain, H., Duderstadt, J., Farrington, G., Goldstein, E., Graves, W., \& Lozier, G. (1999). Dancing with the devil: Information technology and the new competition in higher education. San Francisco: Jossey-Bass.

King, K. P. (2002). Testing the waters for distance education in adult education programs. PAACE Journal of Lifelong Learning, 11, 11-24.

Lin, C. A. (1999). Online service adoption likelihood. Journal of Advertising Research, 79-89.

Liu, Y. (2008). An adoption model for mobile learning Symposium conducted at the meeting of the IADIS International Conference e-Commerce, Amsterdam, Holland.

Liu, Y., Han, S., \& Li, H. (2010). Understanding the factors driving m-learning adoption: a literature review. Campus-Wide Information Systems, 27(4), 210-226.

Liu, Y., Li, H., \& Carlsson, C. (2009). Exploring the factors driving M-learning adoptionAIS. Symposium conducted at the meeting of the AMCIS 2009, San Francisco. Retrieved from http://aisel.aisnet.org/amcis2009/178

Merriam, S. B., \& Caffarella, R. S. (1991). Learning in Adulthood: A comprehensive Guide. San Francisco: Jossey-Bass.

Mondi, M., Woods, P., \& Rafi, A. (2008). A uses and gratification expectancy model to predict students perceived learning experience Educational Technology \& Society, 11(2), 241-261.

Morris, T. A. (2010). Anytime/Anywhere online learning: Does it remove barriers for adult learners? In T. Kidd (Ed.), Online education and adult learning: New frontiers for teaching practices. New York: information Science Reference.

Motiwalla, L. F. (2007). Mobile learning: a framework and evaluation. Computers \& Education, 49, 581-596.

Munro, R. A., \& Rice-Munro, E. J. (2004). Learning Style, teaching Approaches, and Technology. The Journal for Quality and Participations, 27(1), 26-33.

Perse, E. M., \& Courtright, J. A. (1993). Normative images of communication media mass and interpersonal channels in the new media environment. Human Communication Research, 19(4), 485-503.

Petrova, K., \& Li, C. (2009. Focus and setting in mobile learning research: A review of the literature. presented at the meeting of the IBIMA 2009, Kuala Lumpur.

Ruey, S. (2010). A case study of constructivist instructional strategies for adult online learning. British Journal of Educational Technology, 41(5), 706-720.

Ryu, H., \& Parsons, D. (2009). Designing learning activities with mobile technologies. In H. Ryu \& D. Parsons (Eds.), Innovative mobile learning: Techniques and technologies (pp. 1-20). USA: IGI global.

Scornavacca, E., Barnes, S. J., \& Huff, S. L. (2006). Mobile Business Research Published in 2000-2004: Emergence, Current Status, and Future Opportunities. Communications of Association for Information Systems, 17(1).

Siau, K., Lim, E.-P., \& Shen, Z. (2001). Mobile commerce: promise challenges, and research agenda. Journal of Database Management, 12 (3), 4-13.

Song, Y., \& Fox, R. (2005. Integrating m-technology into web-base ESL vocabulary learning for working adult learners. presented at the meeting of the The 3rd IEEE International Workshop on Wireless and Mobile Technologies in Education, Japan. Retrieved from http://hdl.handle.net/10722/47024

Sosik, J. J., Kahai, S. S., \& Piovoso, M. J. (2009). Silver bullet or voodoo statistic? A premier for using the Partial Least Squares data analytic techniques in group and organization 
research. Group \& Organization Management, 34(1), 5-36.

Stafford, T. F. (2005). Understanding motivations for internet use in distance education. IEEE Transactions on education, 48(2), $301-307$.

Stafford, T. F., Stafford, M. R., \& Schkade, L. L. (2004). Determining uses and gratifications for the Internet. Decision Sciences, 35(2), 259-288.

Tenenhaus, M., Vinzi, M. E., Chatelin, Y.-M., \& Lauro, C. (2005). PLS path modelling. Computational Statistics \& Data Analysis 27(1), 19-49.

Wang, Y.-S., Wu, M.-C., \& Wang, H.-Y. (2009). Investigating the determinants and age and gender differences in the acceptance of mobile learning. British Journal of Educational Technology, 40(1), 92-118. 